IOS Press

\title{
Para-hormesis: An innovative mechanism for the health protection brought by antioxidants in wine
}

\author{
Henry Jay Forman ${ }^{\mathrm{a}, \mathrm{b}, *}$ and Fulvio Ursini ${ }^{\mathrm{c}}$ \\ ${ }^{a}$ University of California, Merced, CA, USA \\ ${ }^{\mathrm{b}}$ Andrus Gerontology Center of the Davis School of Gerontology, University of Southern California, \\ Los Angeles, CA, USA \\ ${ }^{\mathrm{c}}$ Department of Molecular Medicine, University of Padova, Padova, Italy
}

\begin{abstract}
We have recently proposed a new paradigm for understanding how antioxidants in fruit and vegetables provide protective effects for health [1]. Here we describe how this new paradigm is relevant to explaining how polyphenols in wine can provide health benefits. The new paradigm of "para-hormesis" is based on the reality that in cells, the by far major antioxidant mechanism is enzyme-catalyzed reduction of hydroperoxides rather than non-enzymatic scavenging of free radicals and other oxidants and that dietary antioxidants increase antioxidant enzymes and their substrates. Indeed, non-enzymatic scavenging by wine polyphenols may be restricted to the intestinal lumen as kinetic considerations rule out a significant contribution of non-enzymatic scavenging in cells. Indeed, antioxidants function through their metabolism in cells to electrophiles that induce antioxidant enzymes and elevate the concentrations of nucleophiles, particular NADPH, glutathione and thioredoxin that are the substrates for these enzymes. This maintenance of "nucleophilic tone" provides the means for "antioxidant defense"
\end{abstract}

\section{Introduction}

We provide here a brief summary of our recent proposal for how polyphenols present in wine, fruit and vegetables provide antioxidant defense in cells. We will also briefly review how wine polyphenols can function in the intestinal lumen in post-prandial consumption. The primary focus however, is on a new paradigm for antioxidant function that we have named para-hormesis.

First, we will define here how we use the terms 'antioxidants,' 'reductants,' 'nucleophiles,' 'oxidants,' and 'electrophiles.' Nucleophiles are molecules that give electrons to other molecules, called electrophiles.

\footnotetext{
${ }^{*}$ Corresponding author: Dr. Henry Jay Forman, Andrus Gerontology Center of the Davis School of Gerontology, University of Southern California, 3715 McClintock Ave, Los Angeles, CA 90089-0191, USA. E-mail: peroxideman@gmail.com.
}

Reductants are then nucleophiles that give one or two electrons to an electrophile, without forming covalent bond. The kind of electrophile that receives electrons from a reductant without forming a covalent bond is then called an oxidant. There are different functional definitions for the word, 'antioxidant.' In chemistry, antioxidants are nucleophilic reductants that directly react with oxidants, thus preventing the oxidation of a third molecule. In biology, antioxidants may act directly or indirectly to increase the capacity to remove electrophiles.

Approximately ten millennia ago humans developed agriculture, which provided availability of nutrients required for maintenance of metabolic energy. Recognition of micronutrients including vitamins that prevented deficiency diseases arose about a century ago although the observation that fruits, vegetables and wine contained substances that enhanced health 
existed in folk traditions well before the advent of modern chemistry. But, the recognition that vegetal foods contain specific phytochemicals that may generally reduce the incidence of disease is quite recent [2-4]. Although their effectiveness was supported by epidemiological, animal and in vitro studies, understanding of how specific phytochemicals provide defense against oxidants developed under some major misconceptions.

Increasing realization that free radical scavenging cannot explain the effects of the beneficial effects of phytochemicals (with the exception of vitamin E) led some investigators to begin investigation into other explanations for the apparent antioxidant activity of these compounds. But, as this was developing, failed clinical trials for antioxidants and controversy surrounding the effects on aging of resveratrol, the polyphenol in wine receiving the most attention, diminished enthusiasm for antioxidants even among scientists in the field of free radical research. Nonetheless, looking at all the studies, including those with negative findings, suggested to some that these compounds have a maximal effectiveness similar to that of vitamins so that supplemental polyphenols and other phytochemicals only provide a benefit to those whose diet is suboptimal in fruits and vegetable consumption. As is clear from increasing obesity and incidence of metabolic syndrome, far too many people consume suboptimal diets.

Wine phytochemicals can be part of the solution, although it may be less common to have a suboptimal diet among moderate wine consumers. Regardless, proposing the use of wine as a supplement to food has been controversial as the contribution of alcohol to both beneficial and deleterious consequences for health provides a whole other set of issues. Here however, we will restrict our discussion to the phytochemicals.

We will describe how the phytochemicals found in wine and vegetal foods activate a signal transduction pathway that results in an increase in the antioxidant enzymes and their substrates, glutathione, thioredoxin and NADPH, which we have named 'nucleophilic tone' [1]. This involves an apparently paradoxical effect in which the phytochemicals are metabolically converted to electrophiles that drive the activation of the Nrf2/EpRE pathway. The literature has many examples of electrophilic compounds producing cellular injury that triggers a hormetic response that provides subsequent protection [5]. Here however, we propose that the phytochemicals produce a "para- hormetic" effect in which there is no toxicity to overcome in increasing nucleophilic tone.

\section{Antioxidants and free radicals}

The ability of a very large number of organic compounds to react rapidly with free radicals has been recognized for almost two centuries and their use in preventing oxidation of polymers and food is of great importance [6]. There is also no argument about the involvement of free radicals in many biological processes both "good" and "bad" [7]. Important examples of the bad side were the observations by Gershman of the involvement of free radicals in radiation damage and its enhancement by oxygen [8] and the development of the free radical theory of aging by Harman [9]. Thus, it was assumed that scavenging with antioxidants could prevent oxidative damage from excessive free radical production and lead to a longer and healthier lifespan. Unfortunately, the syllogism that the more antioxidants one could pack into cells and tissues, the greater would be the resistance to pathology caused by free radicals has run into the hard reality of failure at least in higher animals and in human clinical trials [10-13]. As described below, while the logic seemed reasonable, limited physiological uptake and the kinetics of competition with biological targets cause free radical scavenging by antioxidants to be a negligible component of antioxidant defense in cells. Although still controversial, long term, high dose $\alpha$-tocopherol administration for cardiovascular disease prevention may be the sole exception [14].

Despite the kinetic realities that antioxidants do not work in cells by scavenging free radicals, some investigators persist in reporting studies in which a newly discovered antioxidant is demonstrated to scavenge radicals in vitro, thereby providing the next 'great breakthrough' (sarcasm intended) in antioxidant defense. With the exception of vitamin E and enzymatic dismutation catalyzed by superoxide dismutase, there is actually no evidence of significant defense in cells by free radical scavenging. An explanation for why vitamin $\mathrm{E}$ is an exception in physiologically relevant free radical scavenging, a history of free radical production in carbon tetrachloride toxicity and lipid peroxidation, antioxidant defense, and a review of the chemistry of oxygen that promotes free radical production by phagocytes and mitochondrial metabolism are provided in our recent publication [1]. 


\section{Phytochemical antioxidants versus antioxidant enzymes in antioxidant defense}

Scavenging by antioxidants is a second order reaction in which Reaction rate $=k[A][B]$, where $[\mathrm{A}]$ is antioxidant concentration, [B] the free radical concentration, and $\mathrm{k}$ is the second order rate constant. The most powerful free radical, hydroxyl radical (HO ) reacts with almost all organic molecules with rate constants approaching the rate of their diffusion $\left(>10^{9} \mathrm{M}^{-1} \mathrm{~s}^{-1}\right)[15,16]$. Thus, no scavenger can be protective by reacting with $\mathrm{HO}$. Put another way, to be $50 \%$ effective, the concentration of a scavenger would need to be equal to the concentration of all the other molecules combined. Alkoxyl radicals (RO') that derive from decomposition of lipid hydroperoxides are produced in membranes $[17,18]$. While they react somewhat more slowly with organic molecules than $\mathrm{HO}^{\circ}$, for both $\mathrm{RO}^{\prime}$ and $\mathrm{HO}^{\circ}$ the only efficient protection against them is to prevention of their formation.

The rates of absorption, transport and competition kinetics that limit antioxidant effectiveness in cells do not apply everywhere. Such an exception is in the intestinal lumen where oxidative degradation of food can leading to post-prandial oxidative stress, which has been demonstrated to be clearly prevented by consumption of wine polyphenols with the food [19].

Although intracellular scavenging of free radicals is not an effective mechanism of protection, antioxidant defense can effectively remove the less reactive, but still reactive species hydrogen peroxide $\left(\mathrm{H}_{2} \mathrm{O}_{2}\right)$ and lipid hydroperoxides by enzymatically reducing them to their corresponding alcohols [20,21]. Catalase can dismutate $\mathrm{H}_{2} \mathrm{O}_{2}$ to $\mathrm{H}_{2} \mathrm{O}$ and $\mathrm{O}_{2}$, while peroxidases and peroxiredoxins catalyze the reduction of hydroperoxides using the electrons of nucleophilic thiols, glutathione (GSH) or thioredoxin (Trx) [22]. Cells maintain GSH and Trx in their reduced forms using enzyme-catalyzed reduction by NADPH primarily. The pentose shunt is the primary source of NADPH making glucose the principal "antioxidant" in cells. Thus, by putting the burden of antioxidant defense on two-electron reduction catalyzed by enzymes, nature evolved a far more effective means of protection than one-electron free radical scavenging. Indeed, as $\mathrm{H}_{2} \mathrm{O}_{2}$ and lipid hydroperoxides are the source of $\mathrm{HO}^{\circ}$ and $\mathrm{RO}$, respectively, their removal by the antioxidant enzyme/nucleophilic substrate-dependent system is where two-electron biochemistry prevents one-electron chemistry in cells.
Another misconception is that antioxidants can reduce hydroperoxides in non-enzymatic two electron reactions, efficiently. Indeed thiols, like glutathione have reaction rates with hydroperoxides that are relatively fast for a non-enzymatic reaction, up to $10 \mathrm{M}^{-1} \mathrm{~s}^{-1}$. But, this rate is trivial in comparison with enzymatic reactions catalyzed by various peroxidases and peroxiredoxins that may be $10^{5}$ times or more faster [22]. Therefore, peroxidase- or peroxiredoxincatalyzed reactions using nucleophilic thiols, rather than non-enzymatic two-electron reactions are biologically significant.

\section{Increasing the cellular adaptive response to oxidative challenge brought by electrophiles}

We have defined nucleophilic tone as "the capacity to remove electrophiles through enzyme catalyzed, dynamic flow of reducing equivalents from NADPH, GSH and Trx" [1]. Increasing nucleophilic tone therefore involves increasing the overall potential for cells to respond to an oxidative challenge from electrophiles. Here we will describe the principal means through which cells react to the production of oxidants and how the phytochemicals in wine, fruit and vegetables produce this response.

\section{The paradoxical action of phytochemical antioxidants: Activation of the Electrophile Response element}

So, if the phytochemicals in wine and other edibles do not act as scavengers of oxidants, should we be asking what the epidemiologists have been smoking? The short answer is 'No, because the phytochemicals induce nucleophilic tone.' Indeed, a large number of phytochemicals, including wine polyphenols, induce antioxidant enzymatic systems.

There are two mechanisms through which phytochemicals induce nucleophilic tone. In one, the chemistry is the generation of superoxide $\left(\mathrm{O}_{2}{ }^{-}\right)$ and $\mathrm{H}_{2} \mathrm{O}_{2}$, while in the other, the molecule is, or is metabolized to an electrophile. In other words, paradoxically, phytochemical antioxidants increases nucleophilic tone by increasing electrophile concentration. Fortunately, and the reason we refer to this phenomenon as 'para-hormesis,' the concentrations of electrophiles reached in mammals are well below toxic. 
Amusingly, it is the inability to reach the high concentrations needed to scavenge free radicals that accounts for the lack of toxicity by the phytochemical itself. An example of pathogen-induced hormesis is observed in plants where bacteria and fungi cause a significant increase in the concentrations of phytochemicals so that they become lethal against the parasites and protective of the host [23]; however, the pathways through which phytochemicals kill pathogens versus those that protect mammals are markedly different.

The realization that it was actually the generation of electrophiles that caused the increase in nucleophilic tone came from a consideration of how some compounds considered as planar aromatic antioxidants were able to induce transcription of several genes in the group called of antioxidant enzymes called Phase II enzymes. As we will describe briefly, several studies [24-40]. Demonstrated that phenolic compounds, along with sulforaphane, an isothiocyanate in cruciferous vegetables, increased endogenous antioxidant protection through activation of transcription mediated by what was first called the Antioxidant Response Element (ARE) but is more accurately called the Electrophile Response Element (EpRE).

When polyphenols and other planar aromatic ortho and para hydroquinones are oxidized to quinones (Fig. 1), they generate $\mathrm{O}_{2}{ }^{-}$and $\mathrm{H}_{2} \mathrm{O}_{2}$. Thus, it was reasonably concluded that these species were responsible for gene induction by planar aromatic compounds that were oxidized to phenolic compounds [40]. We now understand that high concentrations, $\mathrm{H}_{2} \mathrm{O}_{2}$ can activate the EpRE [41], but twenty years ago the labs of Talalay [37] and Daniel [39] clearly demonstrated that it was electrophiles, including quinones generated from planar aromatic phenolic compounds that were more likely responsible than $\mathrm{O}_{2}{ }^{-}$or $\mathrm{H}_{2} \mathrm{O}_{2}$ for Phase II enzyme induction.

Once the ARE/EpRE was recognized, the transcription factor(s) that activated it were sought. Nrf2 (NF-E2-related factor 2) was found to be the principal transcription factor that binds to the EpRE in response to activation by electrophiles [42]. Nrf2 is a rapidly turning over protein in the cytosol. This rapid turnover is mediated by Keap1 (Kelch-like ECH-associated protein 1), [43] (also called called INrf2 (inhibitor of Nrf2) [44]), that assists in Nrf2 ubiquitinylation that marks the protein for proteasomal degradation [43]. If critical cysteine residues in Keap1 are alkylated or oxidized, Keap1 cannot facilitate Nrf2 degradation, which allows Nrf2 to translocate to the nucleus [45].
The activation of EpRE by high concentrations of $\mathrm{H}_{2} \mathrm{O}_{2}$ referred to above begins with the formation of a disulfide between two Keap1 molecules [41]. It is however, alkylation of a critical cysteine residue on Keap1 by an electrophile that permits Nrf2 to escape degradation. There are many cysteines in Keap1 but which of these is the critical target appears to depend upon the concentration of the particular electrophile [46-51].

In the nucleus, Nrf2 forms a heterodimer with a partner protein in binding to EpRE. Several studies suggest this is c-Jun [52] while others claim it is a small Maf protein [53]. Furthermore, phosphorylation of Nrf2 is required for translocation to the nucleus and activation of EpRE-regulated gene transcription [54-60].

\section{Wine polyphenols in para-hormesis}

Depending upon the type of grape and many other factors, the polyphenol content of wine varies widely. Rather than reviewing the individual chemistries of hundreds of compounds, we will review the general chemical issues and focus on resveratrol, which has attracted considerable attention and is even being used as a supplement in some wine and as a nutraceutical in capsule form.

A principle consideration for the chemistry shown in Fig. 1 is that the polyphenol must have two hydroxyl groups in ortho or para relationship in order to redox cycle to produce $\mathrm{O}_{2}{ }^{-}$and $\mathrm{H}_{2} \mathrm{O}_{2}$ and form the quinone. The general structure that acts as the electrophile is the $\alpha, \beta$-unsaturated carbonyl $(\mathrm{RHC}=\mathrm{CH}-\mathrm{CR}=\mathrm{O})$ moiety. This undergoes a Michael addition with a cysteine that is in the thiolate $\left(\mathrm{S}^{-}\right.$) form (Fig. 2). It has been suggested that in Keap1, zinc coordinating to cysteine, delocalizes the proton and thus increases the nucleophilicity, accounts for its greatly enhanced sensitivity to electrophiles than protein cysteines in general [61]. Thus, in a sea of cysteines, the zinc-coordinated cysteine residues of Keap1 can act as a sensor.

While many of the polyphenols in wine would be expected to act through the chemistry in 2, resveratrol cannot! This is because resveratrol (Fig. 3) is has a meta-hydroquinone and a phenol structure and cannot be oxidized to form the $\alpha, \beta$-unsaturated carbonyl structure. Nonetheless, as also shown in Fig. 3, enzymatic oxidation of the phenol moiety by tyrosinase [62] can form the ortho hydroquinone. The 3-hydroxyresveratrol can be a precursor to form- 


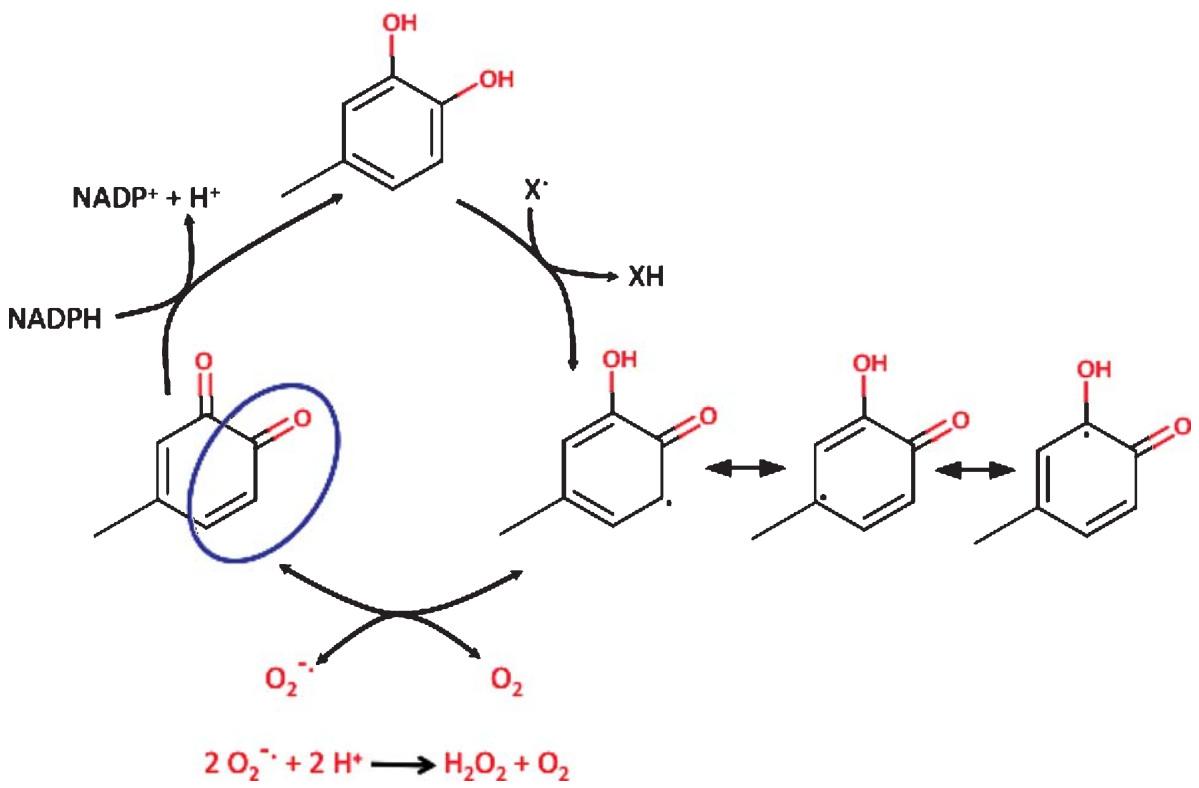

Fig. 1. General scheme for redox cycling and the generation of electrophilic quinones.

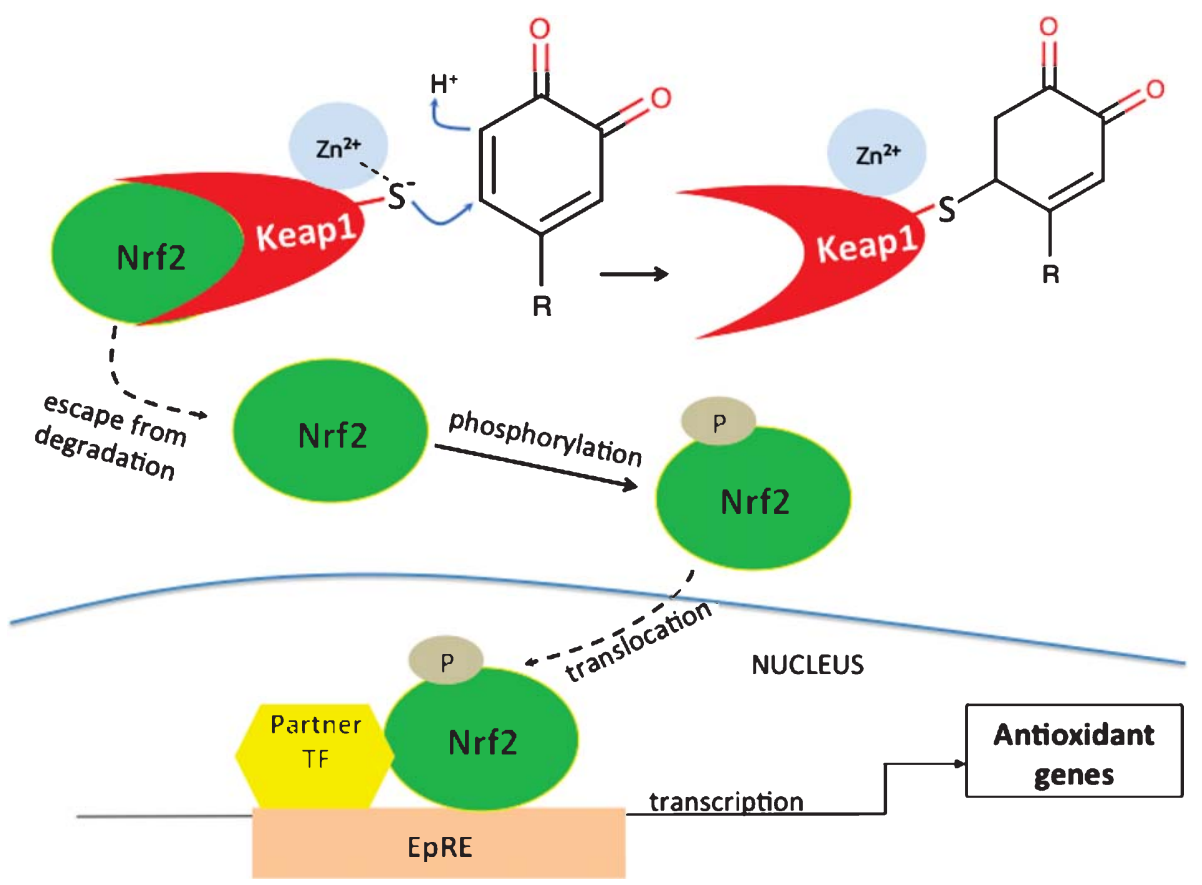

Fig. 2. Keap1 reacts with $\alpha, \beta$-carbonyl moiety in a Michael addition. Enhancement by Zn.

ing the $\alpha, \beta$-unsaturated carbonyl structure that then reacts with Keap1 (Fig. 2). As a caveat to this entire discussion, it should be noted that resveratrol, as well as other polyphenols affect other signaling path- ways besides the Nrf2/EpRE pathway; however, the effect on nucleophilic tone through the Nrf2/EpRE pathway can account at least for much of these effects. 


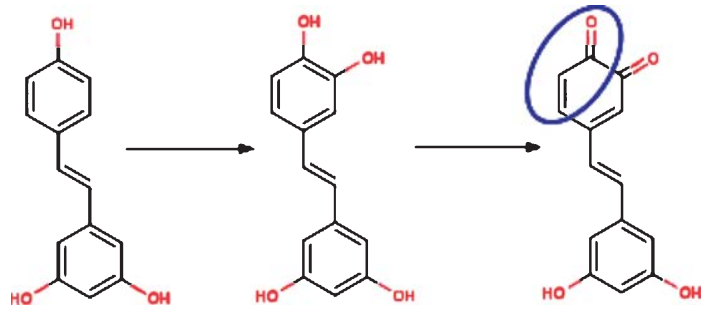

Fig. 3. Resveratrol oxidation.

\subsection{Nucleophilic tone, inflammation and health}

Life is self-protecting and reactions to agents that produce injury vary with the ability of cells to defend themselves [63]. The basic elements of inflammation as a "reaction to an injury" consist of an array of mechanisms designed to eliminate stimuli, repair tissues through elimination of the most damaged cells, and proliferate. Remarkably, a large number of these events operate through oxidative reactions in a network of redox signaling $[63,64]$. Indeed, in a general view, inflammation as response to injury evolves with the formation of electrophiles. This deviation from redox homeostasis is often referred to as 'oxidative stress.'

An excessive or inappropriate response to a given physiological challenge can lead to the prolonged alteration of homeostasis we classify as disease. Cancer, liver and lung fibrosis, neurodegeneration, and other diseases of aging., can all be seen as the outcome of excessive activation of responses to injury. Surveying the enormous amount of literature on nutraceutical effects of natural compounds and recognition of the value of these compounds in folk medicine around the world, produces a leitmotif relative to regulation of inflammation and protection from chronic degenerative diseases [3] and cancer [65, 66] by nutritional phytochemicals.

In conclusion, we propose the name 'ParaHormesis' to describe the process by which nutritional antioxidants optimize the cellular defense system by mimicking electrophiles and increasing the Nucleophilic Tone, preventing in this way diseases generated by an excess of inflammatory response [63]. While presenting 'Para-Hormesis' as a paradigm shift in understanding physiological mechanisms of action by nutritional antioxidants we are happy to recall, besides modern epidemiology, the ancient wisdom describing the health protective effect of wine which is certainly one of the major sources of "nutritional antioxidants".

\section{References}

[1] Forman HJ, Davies KJ, Ursini F. How do nutritional antioxidants really work: Nucleophilic tone and para-hormesis versus free radical scavenging in vivo. Free Radical Biology and Medicine 2013. PubMed PMID: 23747930. Epub 2013/06/12. Eng.

[2] Craig WJ. Phytochemicals: Guardians of our health. J Am Diet Assoc 1997;97(10 Suppl 2):S199-204.

[3] Spencer JP. The impact of fruit flavonoids on memory and cognition. The British Journal of Nutrition 2010;104(Suppl 3):S40-7. PubMed PMID: 20955649. Epub 2010/10/20. eng.

[4] DeWeerdt S. Food: The omnivore's labyrinth. Nature 2011;471(7339):S22-4. PubMed PMID: 21430718. Epub 2011/03/25. eng.

[5] Hayes DP. Nutritional hormesis. European Journal of Clinical Nutrition 2007;61(2):147-59. PubMed PMID: 16885926. Epub 2006/08/04. eng.

[6] Scott G. Antioxidants in science, technology, medicine and nutrition. Chichester, UK: Albion Publishing, 1997;334.

[7] Beckman KB, Ames BN. The free radical theory of aging matures. Physiol Rev 1998;78(2):547-81. PubMed PMID: 9562038. Epub 1998/04/30. eng.

[8] Gerschman R, Gilbert DL, Nye SW, Dwyer P, Fenn WO. Oxygen poisoning and $\mathrm{x}$-irradiation: A mechanism in common. Science 1954;119(3097):623-6. PubMed PMID: 13156638. Epub 1954/05/07. eng.

[9] Harman D. Aging: A theory based on free radical and radiation chemistry. Journal of Gerontology 1956;11(3):298-300. PubMed PMID: 13332224. Epub 1956/07/01. eng.

[10] Muller FL, Lustgarten MS, Jang Y, Richardson A, Van Remmen $\mathrm{H}$. Trends in oxidative aging theories. Free Radical Biology and Medicine 2007;43(4):477-503. PubMed PMID: 17640558. Epub 2007/07/21. eng.

[11] Warnholtz A, Munzel T. Why do antioxidants fail to provide clinical benefit? Curr Control Trials Cardiovasc Med 2000;1(1):38-40. PubMed PMID: 11714406. Pubmed Central PMCID: 59596. Epub 2001/11/21. Eng.

[12] Omenn GS, Goodman GE, Thornquist MD, Balmes J, Cullen MR and Glass A. et al. Effects of a combination of beta carotene and vitamin A on lung cancer and cardiovascular disease. New England Journal of Medicine 1996;334(18):1150-5.

[13] Winterbourn CC. Reconciling the chemistry and biology of reactive oxygen species. Nature Chemical Biology 2008;4(5):278-86. PubMed PMID: 18421291. Epub 2008/ 04/19. eng.

[14] Roberts Ii LJ, Traber MG, Frei B, Vitamins E, C. in the prevention of cardiovascular disease and cancer in men. Free Radical Biology and Medicine 2009;46(11):1558.

[15] Dorfman LM, Adams DO. Reactivity of Hydroxyl Radicals in Aquesous Solution. National Standard Reference Data System: US Dept Commerce, Natl. Bureau Standards 1973;1-59.

[16] Haag WR, Yao CCD. Rate constants for reaction of hydroxyl radicals with several drinking water contaminants. Environ Sci Technol 1992;26:1005-13.

[17] Carlsson DJ, Howard JA, Ingold KU. Reactions of alkoxy radicals. II. The absolute rate constant for the combination of t-butoxy radicals. J Am Chem Soc 1966;88:4725-6.

[18] Buettner GR. The pecking order of free radicals and antioxidants: Lipid peroxidation, $\alpha$-tocopherol, and ascor- 
bate. Archives of Biochemistry and Biophysics 1993;300: 535-43.

[19] Ursini F, Sevanian A. Postprandial oxidative stress. Biol Chem. 2002;383(3-4):599-605. PubMed PMID: 12033449. Epub 2002/05/30. eng.

[20] Maiorino M, Coassin M, Roveri A, Ursini F. Microsomal lipid peroxidation: Effect of vitamin $\mathrm{E}$ and its functional interaction with phospholipid hydroperoxide glutathione peroxidase. Lipids 1989;24(8):721-6. PubMed PMID: 2586229. Epub 1989/08/01. eng.

[21] Ursini F, Maiorino M, Brigelius-Flohe R, Aumann KD, Roveri A, Schomburg D, et al. Diversity of glutathione peroxidases. Methods in Enzymology 1995;252:38-53. PubMed PMID: 7476373. Epub 1995/01/01. eng.

[22] Flohe L, Toppo S, Cozza G, Ursini F. A comparison of thiol peroxidase mechanisms. Antioxidants \& Redox Signaling 2011;15(3):763-80. PubMed PMID: 20649470. Epub 2010/07/24. eng.

[23] Howitz KT, Sinclair DA. Xenohormesis: Sensing the chemical cues of other species. Cell 2008;133(3):387-91. PubMed PMID: 18455976. Pubmed Central PMCID: 2504011. Epub 2008/05/06. eng.

[24] Mulcahy RT, Gipp JJ. Identification of a putative antioxidant response element in the 5'-flanking region of the human $\mathrm{g}$ glutamylcycteine synthetase heavy subunit gene. Biochemical and Biophysical Research Communications 1995;209:227-33.

[25] Moinova HR, Mulcahy RT. An electrophile responsive element (EpRE) regulates $\beta$-naphthoflavone induction of the human g-glutamylcysteine synthetase regulatory subunit gene. Constitutive expression is mediated by an adjacent AP-1 site. The Journal of Biological Chemistry 1998;273(24):14683-9.

[26] Wild AC, Mulcahy RT. Regulation of gamma-glutamylcysteine synthetase subunit gene expression: Insights into transcriptional control of antioxidant defenses. Free Radical Research 2000;32(4):281-301. PubMed PMID: 10741850.

[27] Rahman I, Antonicelli F, MacNee W. Molecular mechanism of the regulation of glutathione synthesis by tumor necrosis factor-alpha and dexamethasone in human alveolar epithelial cells. The Journal of Biological Chemistry 1999;274(8):508896. PubMed PMID: 9988757.

[28] Rahman I, Bel A, Mulier B, Lawson MF, Harrison DJ, MacNee W, et al. Transcriptional regulation of $\gamma$-glutamylcysteine synthetase-heavy subunit by oxidants in human aveolar epithelial cells. Biochemical and Biophysical Research Communications 1996;229:832-7.

[29] Sekhar KR, Meredith MJ, Kerr LD, Soltaninassab SR, Spitz DR, Xu Z-Q, et al. Expression of glutathione and $\gamma$-glutamylcysteine synthetase mRNA is Jun dependent. Biochemical and Biophysical Research Communications 1997; 234:588-93.

[30] Tanaka T, Uchiumi T, Kohno K, Tomonari A, Nishio K, Saijo $\mathrm{N}$, et al. Glutathione homeostasis in human hepatic cells: Overexpression of $\gamma$-glutamylcysteine synthetase gene in cell lines resistant to buthionine sulfoximine, an inhibitor of glutathione synthesis. Biochemical and Biophysical Research Communications 1998;246:398-403.

[31] Tomonari A, Nishio K, Kurokawa H, Arioka H, Ishida T, Fukumoto H, et al. Identification of cis-acting DNA elements of the human $\gamma$-glutamylcysteine synthetase heavy subunit gene. Biochemical and Biophysical Research Communications 1997;232:522-7.

[32] Dickinson DA, Iles KE, Watanabe N, Iwamoto T, Zhang H, Krzywanski DM, et al. 4-hydroxynonenal induces glutamate cysteine ligase through JNK in HBE1 cells. Free Radical Biology and Medicine 2002;33(7):974-87. PubMed PMID: 12361807.

[33] Dickinson DA, Iles KE, Zhang H, Blank V, Forman HJ. Curcumin alters EpRE and AP-1 binding complexes and elevates glutamate-cysteine ligase gene expression. Faseb J 2003;17(3):473-5. PubMed PMID: 12514113.

[34] Tu Z, Anders MW. Up-regulation of glutamate-cysteine ligase gene expression by butylated hydroxytoluene is mediated by transcription factor AP-1. Biochemical and Biophysical Research Communications 1998;244(3):801-5. PubMed PMID: 9535746.

[35] Mathers J, Fraser JA, McMahon M, Saunders RD, Hayes JD, McLellan LI. Antioxidant and cytoprotective responses to redox stress. Biochemical Society Symposium 2004;(71):15776. PubMed PMID: 15777020. Epub 2005/03/22. eng.

[36] Sykiotis GP, Bohmann D. Stress-activated cap'n'collar transcription factors in aging and human disease. Sci Signal. 2010;3(112):re3. PubMed PMID: 20215646. Epub 2010/03/11. eng.

[37] Prochaska HJ, Talalay P. Regulatory mechanisms of monofunctional and biofunctional anticarcinogenic enzyme inducers in murine liver. Cancer Research 1988;48:4776-82.

[38] Paulson KE, Darnell JE, Rushmore T, Pickett CB. Analysis of the upstream elements of the xenobiotic compound- inducible and positionally regulated glutathione S-transferase Ya gene. Molecular and Cellular Biology 1990;10(5):1841-52.

[39] Friling RS, Bensimon A, Tichauer Y, Daniel V. Xenobioticinduced expression of murine glutathione S- transferase Ya subunit gene is controlled by an electrophile- responsive element. Proceedings National Academy of Sciences, USA. 1990;87:6258-62.

[40] Rushmore TH, Morton MR, Pickett CB. The antioxidant responsive element. Activation by oxidative stress and identification of the DNA consensus sequence required for functional activity. Journal of Biological Chemistry 1991;266: 11632-9.

[41] Fourquet S, Guerois R, Biard D, Toledano MB. Activation of NRF2 by nitrosative agents and $\mathrm{H} 2 \mathrm{O} 2$ involves KEAP1 disulfide formation. The Journal of Biological Chemistry 2010;285(11):8463-71. PubMed PMID: 20061377. Pubmed Central PMCID: 2832995. Epub 2010/01/12. eng.

[42] Itoh K, Chiba T, Takahashi S, Ishii T, Igarashi K, Katoh $\mathrm{Y}$, et al. An Nrf2/small Maf heterodimer mediates the induction of phase II detoxifying enzyme genes through antioxidant response elements. Biochemical and Biophysical Research Communications 1997;236(2):313-22. PubMed PMID: 9240432. Epub 1997/07/18. eng.

[43] Itoh K, Wakabayashi N, Katoh Y, Ishii T, Igarashi K, Engel JD, et al. Keap1 represses nuclear activation of antioxidant responsive elements by Nrf2 through binding to the aminoterminal Neh2 domain. Genes \& Development 1999;13(1):7686. PubMed PMID: 9887101.

[44] Dhakshinamoorthy S, Jaiswal AK. Functional characterization and role of INrf2 in antioxidant response element- 
mediated expression and antioxidant induction of $\mathrm{NAD}(\mathrm{P}) \mathrm{H}$ : Quinone oxidoreductase1 gene. Oncogene 2001;20(29):390617. PubMed PMID: 11439354. Epub 2001/07/06. eng.

[45] Zhang DD, Hannink M. Distinct cysteine residues in Keap1 are required for Keap1-dependent ubiquitination of Nrf2 and for stabilization of Nrf2 by chemopreventive agents and oxidative stress. Mol Cell Biol 2003;23(22):8137-51. PubMed PMID: 14585973.

[46] Hong F, Sekhar KR, Freeman ML, Liebler DC. Specific patterns of electrophile adduction trigger Keap1 ubiquitination and Nrf2 activation. The Journal of Biological Chemistry 2005;280(36):31768-75. PubMed PMID: 15985429. Epub 2005/06/30. eng.

[47] Hong F, Freeman ML, Liebler DC. Identification of sensor cysteines in human Keap1 modified by the cancer chemopreventive agent sulforaphane. Chemical Research in Toxicology 2005;18(12):1917-26. PubMed PMID: 16359182. Epub 2005/12/20. eng.

[48] Hur W, Gray NS. Small molecule modulators of antioxidant response pathway. Curr Opin Chem Biol 2011;15(1):162-73. PubMed PMID: 21195017. Epub 2011/01/05. eng.

[49] Luo Y, Eggler AL, Liu D, Liu G, Mesecar AD, van Breemen RB. Sites of alkylation of human Keap1 by natural chemoprevention agents. Journal of the American Society for Mass Spectrometry 2007;18(12):2226-32. PubMed PMID: 17980616. Pubmed Central PMCID: 2144741. Epub 2007/ 11/06. eng.

[50] Ohnuma T, Nakayama S, Anan E, Nishiyama T, Ogura K, Hiratsuka A. Activation of the Nrf2/ARE pathway via Salkylation of cysteine 151 in the chemopreventive agent-sensor Keap1 protein by falcarindiol, a conjugated diacetylene compound. Toxicology and Applied Pharmacology 2010;244(1):27-36. PubMed PMID: 20026152. Epub 2009/ $12 / 23$. eng.

[51] Rachakonda G, Xiong Y, Sekhar KR, Stamer SL, Liebler DC, Freeman ML. Covalent modification at Cys151 dissociates the electrophile sensor Keap1 from the ubiquitin ligase CUL3. Chemical Research in Toxicology 2008;21(3):705-10. PubMed PMID: 18251510. Epub 2008/02/07. eng.

[52] Venugopal R, Jaiswal AK. Nrf2 and Nrf1 in association with Jun proteins regulate antioxidant response element-mediated expression and coordinated induction of genes encoding detoxifying enzymes. Oncogene 1998;17(24):3145-56.

[53] Itoh K, Igarashi K, Hayashi N, Nishizawa M, Yamamoto M. Cloning and characterization of a novel erythroid cell-derived CNC family transcription factor heterodimerizing with the small Maf family proteins. Mol Cell Biol 1995;15(8):4184-93. PubMed PMID: 7623813. Pubmed Central PMCID: 230657. Epub 1995/08/01. eng.

[54] Huang HC, Nguyen T, Pickett CB. Regulation of the antioxidant response element by protein kinase C-mediated phosphorylation of NF-E2-related factor 2. Proc Natl Acad Sci U S A 2000;97(23):12475-80. PubMed PMID: 11035812. Pubmed Central PMCID: 18788. Epub 2000/10/18. eng.

[55] Jaiswal AK. NRF2 signaling in coordinated activation of antioxidant genes expression. Free Radical Biology and Medicine 2004;36:1199-207.
[56] Kang KW, Choi SH, Kim SG. Peroxynitrite activates NFE2-related factor 2/antioxidant response element through the pathway of phosphatidylinositol 3-kinase: The role of nitric oxide synthase in rat glutathione S-transferase A2 induction. Nitric Oxide : Biology and Chemistry/Official Journal of the Nitric Oxide Society 2002;7(4):244-53. PubMed PMID: 12446173. Epub 2002/11/26. eng.

[57] Martin D, Rojo AI, Salinas M, Diaz R, Gallardo G, Alam $\mathrm{J}$, et al. Regulation of heme oxygenase-1 expression through the phosphatidylinositol 3-kinase/Akt pathway and the Nrf2 transcription factor in response to the antioxidant phytochemical carnosol. The Journal of Biological Chemistry 2004;279(10):8919-29. PubMed PMID: 14688281.

[58] Zhang H, Forman HJ. Acrolein induces heme oxygenase-1 through PKC-delta and PI3K in human bronchial epithelial cells. Am J Respir Cell Mol Biol 2008;38(4):483-90. PubMed PMID: 18048804. Epub 2007/12/01. eng.

[59] Bloom DA, Jaiswal AK. Phosphorylation of Nrf2 at Ser40 by protein kinase $\mathrm{C}$ in response to antioxidants leads to the release of $\mathrm{Nrf} 2$ from INrf2, but is not required for Nrf2 stabilization/accumulation in the nucleus and transcriptional activation of antioxidant response element-mediated NAD(P)H: Quinone oxidoreductase-1 gene expression. The Journal of Biological Chemistry 2003;278(45):44675-82. PubMed PMID: 12947090. Epub 2003/08/30. eng.

[60] Niture SK, Jain AK, Jaiswal AK. Antioxidant-induced modification of INrf2 cysteine 151 and PKC-delta-mediated phosphorylation of Nrf2 serine 40 are both required for stabilization and nuclear translocation of $\mathrm{Nrf} 2$ and increased drug resistance. Journal of Cell Science 2009;122(Pt 24):445264. PubMed PMID: 19920073. Pubmed Central PMCID: 2787459. Epub 2009/11/19. eng.

[61] Dinkova-Kostova AT, Holtzclaw WD, Wakabayashi N. Keap1, the sensor for electrophiles and oxidants that regulates the phase 2 response, is a zinc metalloprotein. Biochemistry 2005;44(18):6889-99. PubMed PMID: 15865434. Epub 2005/05/04. eng.

[62] Bernard P, Berthon JY. Resveratrol: An original mechanism on tyrosinase inhibition. International Journal of Cosmetic Science 2000;22(3):219-26. PubMed PMID: 18503477. Epub 2008/05/28. eng.

[63] Medzhitov R. Origin and physiological roles of inflammation. Nature 2008;454(7203):428-35. PubMed PMID: 18650913. Epub 2008/07/25. eng.

[64] Brigelius-Flohe R, Flohe L. Basic Principles and Emerging Concepts in the Redox Control of Transcription Factors. Antioxidants \& Redox Signaling 2011. PubMed PMID: 21194351. Epub 2011/01/05. Eng.

[65] Surh YJ. Cancer chemoprevention with dietary phytochemicals. Nat Rev Cancer 2003;3(10):768-80. PubMed PMID: 14570043. Epub 2003/10/23. eng.

[66] Gupta SC, Kim JH, Prasad S, Aggarwal BB. Regulation of survival, proliferation, invasion, angiogenesis, and metastasis of tumor cells through modulation of inflammatory pathways by nutraceuticals. Cancer Metastasis Rev 2010;29(3):40534. PubMed PMID: 20737283. Pubmed Central PMCID: 2996866. Epub 2010/08/26. eng. 